\title{
Development of an isotope ratio laser spectrometer for rapid and precise clumped isotope measurement: progress and performance
}

\author{
ZHENNAN WANG ${ }^{1}$, NITZAN YANAY ${ }^{1}$, DAVID \\ DETTMAN $^{1}$, JAY QUADE ${ }^{1}$, DAVID NELSON ${ }^{2}$, J. $^{2}$ \\ MCMANUS $^{2}$, KATHARINE HUNTINGTON ${ }^{3}$, ANDREW \\ SCHAUER $^{3}$ AND SABURO SAKAI ${ }^{4}$ \\ ${ }^{1}$ University of Arizona \\ ${ }^{2}$ Aerodyne Research, Inc. \\ ${ }^{3}$ University of Washington \\ ${ }^{4}$ Japan Agency for Marine-Earth Science and Technology \\ Presenting Author: zwang535@arizona.edu
}

Time-consuming measurement, large sample size, and assumptions regarding ${ }^{17} \mathrm{O}$ corrections limit the broad application of carbonate clumped isotope research. We report our recent progress in development of an isotope ratio laser spectrometry instrument based on tunable infrared laser differential absorption spectroscopy (TILDAS). The instrument has three main sections: a gas extraction/dehydration line, a $\mathrm{CO}_{2}$ sample mixing and delivery system, and a TILDAS dual laser instrument for the isotopologue suite measurement. The gas extraction line follows widespread methods for carbonate-phosphoric acid reaction and then purifies the $\mathrm{CO}_{2}$ gas by cryogenically removing water vapor and non-condensable gases. The sample introduction system thoroughly mixes $\mathrm{CO}_{2}$ gas with $\mathrm{N}_{2}$ gas (which is a unique feature of our laser spectroscopic method) and loads the mixture into the TILDAS instrument for individual measurement of four $\mathrm{CO}_{2}$ isotopologues $\quad\left({ }^{16} \mathrm{O}^{12} \mathrm{C}^{16} \mathrm{O}, \quad{ }^{16} \mathrm{O}^{13} \mathrm{C}^{16} \mathrm{O}, \quad{ }^{16} \mathrm{O}^{12} \mathrm{C}^{18} \mathrm{O}\right.$, and ${ }^{16} \mathrm{O}^{13} \mathrm{C}^{18} \mathrm{O}$ ). The measurements are compared to a working reference gas. The addition of $\mathrm{N}_{2}$ gas widens the absorption peaks and improves the high precision measurement of absorption peak areas. Isotopologues associated with ${ }^{17} \mathrm{O}$ are not present in the peaks measured for the clumped isotope calculation. This automated TILDAS instrument is competitive with the best isotope ratio mass spectrometry (IRMS) systems and surpasses typical IRMS measurements in several key respects, such as rapid and precise measurement $(0.01 \%$ within 45 minutes per carbonate sample, 1 S.E. $)$, small sample size $(<20$ $\mu \mathrm{mol}$ of $\mathrm{CO}_{2},<2 \mathrm{mg}$ equivalent calcite), and no isobaric interferences. The reported TILDAS $\Delta_{16013 \mathrm{C} 180}$ values, approximately equivalent to $\Delta_{47}$, show a linear relationship with the theoretical values. Synthetic carbonates grown at controlled temperatures are used to establish an empirical $\Delta_{16013 \mathrm{C}_{180}}{ }^{-}$ temperature calibration. Long-term drift is significantly reduced, and one standard deviation of $0.023 \%$ o $(n=70)$ is observed in the measurement of a laboratory carbonate standard (Carrara marble) over a period of 3 months. An automated sample processing system, projected to measure 20 unknowns in a 24 hour period, is nearly completed and we will report on the total throughput and precision of this system. 